are made possible by the generous contributions of donors, leaders, and partners, such as you.

For more information or to make a contribution, visit the AATS Foundation Web site: www.aatsfoundation. org, or contact the AATS Development office: 978-
252-2200, Ext 544. Be assured, 100 percent of your individual gift will go directly to programs and will have a lasting impact on the cardiothoracic community.

Thank you for your thoughtful consideration.

\section{The Western Thoracic Surgical Association}

\section{WTSA 45th Annual Meeting}

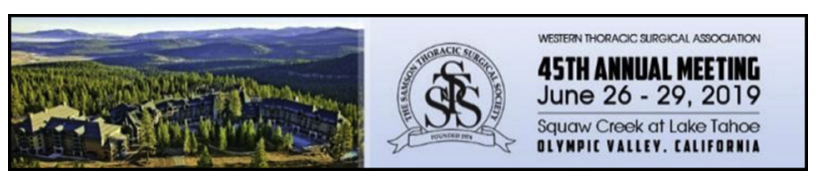

\section{Call for Abstracts}

The WTSA's 45th Annual Meeting will be held at Squaw Creek at Lake Tahoe in Olympic Valley, California, from June 26 to 29, 2019. Abstract submissions are now being accepted for presentation consideration at the 2019 WTSA Annual Meeting through Monday, January 7, 2019, at 11:59 PM Pacific Standard Time. Visit the WTSA Web site at westernthoracic.org to view author instructions and to submit abstracts.

\section{WTSA Traveling Fellowship for Residents, Trainees, and Practicing Surgeons}

The goal of this traveling fellowship is to promote interaction and learning between residents/trainees/practicing surgeons and WTSA members. The traveling fellow will visit a University-affiliated or academic practice of his/her choosing, within the boundaries of the WTSA (Alaska, Arizona, California, Colorado, Hawaii, Idaho, Montana, Nevada, New Mexico, Oregon, Utah, Washington, and Wyoming, along with Canadian provinces of Alberta, British Columbia, Manitoba, and Saskatchewan), for a period of one to two weeks, under the sponsorship of a Western member at the hosting institution. The traveling fellow does not need to be a WTSA member; the award is open to any resident/trainee/practicing surgeon. More details are available at westernthoracic.org.

\section{Applications for WTSA Membership}

The WTSA is now accepting Applications for Membership online for Active as well as Candidate membership status for the 2019 membership cycle. Visit the WTSA Web site at www.westernthoracic.org to read the complete membership eligibility requirements and to initiate an online application.

\section{Active Member}

$\$ 375.00$ annually, plus $\$ 50.00$ initiation fee Applicant must meet all membership criteria, including but not limited to:

- Reside within or have completed a cardiothoracic residency training program within the geographic limits of the Association.

- Have been engaged in the practice of thoracic and cardiovascular surgery for at least three years following completion of postgraduate training. If a candidate completed his/her thoracic surgical residency or a one-year clinical fellowship in an institution within the geographic limits of the Association, such completion may count toward one of the three years of practice.

- Have a full and unrestricted license to practice medicine in his or her respective state or province, and have a current appointment on the surgical staff of a hospital with no reportable action pending which could adversely affect such applicant's staff privileges at any hospital.

\section{Candidate Member}

$\$ 100.00$ annually

Applicant must meet all membership criteria, including but not limited to:

- Be matched or enrolled in either a cardiothoracic surgery education program accredited by the Residency Review Committee for Thoracic Surgery under the authority of the ACGME or a program approved for cardiothoracic surgery education by the Royal College of Surgeons of Canada—or their equivalency-from within the Association's geographic limits. Individuals who have completed their education in one of the above programs but do not yet meet all of the criteria for Active membership also are eligible to apply for Candidate membership. Individuals who trained outside the Association's geographic limits who are now residing within the Association's boundaries but do not yet have three years in practice may also apply for Candidate membership.

An application must include the following uploads: a photo, a complete curriculum vitae with bibliography, 